\title{
ABATEMENT OF MICROPLASTICS FROM MUNICIPAL EFFLUENTS BY TWO DIFFERENT WASTEWATER TREATMENT TECHNOLOGIES
}

\author{
JAVIER BAYO, JOAQUÍN LÓPEZ-CASTELLANOS \& SONIA OLMOS \\ Department of Chemical and Environmental Engineering, Technical University of Cartagena, Spain
}

\begin{abstract}
This paper discusses the role of two different wastewater treatment technologies in the removal efficiency of microplastics from the final effluent of an urban wastewater treatment plant; i.e., a membrane bioreactor as an advanced wastewater treatment technology and rapid sand filtration as a tertiary treatment after an activated sludge process. Fourteen different polymer types were identified in all wastewater samples, mainly represented by low-density polyethylene $(71.89 \%)$, high-density polyethylene $(5.44 \%)$, acrylate $(5.24 \%)$, polypropylene $(5.22 \%)$, polystyrene $(4.24 \%)$, and nylon $(2.56 \%)$. The main forms isolated were fibres $(61.2 \%)$, followed by films $(31.5 \%)$, fragments $(6.7 \%)$, and beads $(0.6 \%)$. The main size interval corresponded to 1 and $2 \mathrm{~mm}$, accounting for $28.2 \%, 37.3 \%$, and $36.8 \%$ for the influent, membrane bioreactor, and rapid sand filtration, respectively. A total of 480 microplastic particles were isolated in all wastewater samples, with an average concentration of $2.16 \pm$ 0.42 items $1^{-1}$, and removal rate percentages of $79.01 \%$ for the membrane bioreactor and $75.49 \%$ for rapid sand filtration. Both technologies proved to be more efficient removing particulate microplastics ( $98.83 \%$ and $95.53 \%$, respectively) than fibres $(57.61 \%$ and $53.83 \%$, respectively), showing a clear escape into the aquatic environment for fibres. The average microplastic size displayed a statistically significant increase from the influent of the sewage treatment plant $(1.05 \pm 0.05 \mathrm{~mm})$, to rapid sand filtration effluent $(1.15 \pm 0.08 \mathrm{~mm})$ and membrane bioreactor $(1.39 \pm 0.15 \mathrm{~mm})(F$-test $=4.014$, $p=0.019)$ indicating the fibre selection made by advanced treatment technologies previously discussed. Keywords: microlitter, microplastics, $M B R, R S F$, wastewater.
\end{abstract}

\section{INTRODUCTION}

Microplastics as a global water pollutant was identified a long time ago, since Carpenter and Smith [1] first described the presence of tiny plastic particles floating in the Sargasso Sea, a region in the North Atlantic Ocean without land boundaries, although the term "microplastic" was first introduced in scientific references by Thompson et al. [2]. They consist of plastic particles smaller than $5 \mathrm{~mm}$, and are classified as primary and secondary microplastics; first of them intentionally produced in that size, and secondary ones generated from the degradation of larger plastic fragments [3]. Its incredibly mobility and ubiquity in the environment represents a global threaten, affecting, of course, the oceans, but also surface waters [4], soils [5], sediments [6], food [7], [8], drinking water [9] or air [10]. Their potential toxicological effect, acting as vectors of both organic and inorganic additives and chemicals [11], [12] are also important reasons for their removal in the environment, besides the presence of residual monomers, as styrene monomer in polystyrene microplastic particles [13].

Wastewater treatment plants (WWTPs) act as a sink or solution to remove microplastics, but also as a source because of wastewater effluents load. Several sources have been pointed out as responsible for the presence of micropalstics in WWTPs, both domestic and non-domestic ones. Domestic washing machines are prone to release fibres from synthetic textiles. Browne et al. [14] reported a production of 1,900 fibres per wash by a single garment, Almroth et al. [15] found average concentrations of 7,360 fibres $\mathrm{m}^{-2} \mathrm{l}^{-1}$ in polyester fleece fabrics and 110,000 fibres per garment and wash for PET fleece, and De Falco et al. [16] 
reported an average of 6,000,000 fibres from typical $5 \mathrm{~kg}$ was load of polyester fabrics. Besides microplastics released from synthetic fabrics, the use of microspherules in personal care products as a substitute for natural scrubs and with a concentration ranging from 0.5 to $5 \%$ [17], may also be released as microbeads from WWTPs. Moreover, paint scraps, pellets from plastic industries, tire wreckage or microparticles from plastics consumer goods indeed reach the sewage treatment, causing the WWTPs to act both as a source and a sink for these micropollutants [18], [19].

The efficiency of different treatment technologies for the removal of microplastics in wastewater has also been reported, although some of them on a pilot scale or with short periods of analysis, that could not reveal actual seasonal variations in their counts [20]. Membrane bioreactor (MBR) has proved to be an established technology for the treatment of both municipal and industrial wastewater, with a high mixed-liqueur suspended solids concentration that may benefit nitrifying and other slow-growing microorganisms [21]. This technology has been tested for microplastic removal, both in real WWTPs [22] or in a pilot-scale bioreactor [20]. On the other hand, rapid sand filtration (RSF) as a tertiary treatment in WWTPs has also been tested. Hidayaturrahmanh and Lee [3] reported the smallest rate of microplastic removal when compared with the use of ozone as a strong oxidant or a membrane disc-filter.

Microplastics in WWTPs have been recognized only by visual identification [3], [23], or with the aid of spectrometric methods; i.e., Raman [20] or $\mu$-Raman [24] spectroscopy, or Fourier transform infrared spectroscopy (FTIR) [19] or $\mu$-FTIR [25], analysing all isolated microparticles [19] or just a part of them [26]. In our study, we present the removal rates of microplastics and treatment efficiencies of two different wastewater treatment technologies; i.e. MBR and RSF, both applied to the same influent in a sewage treatment plant located in the Southeast of Spain. Analyses were carried out with visual identification and FTIR confirmation.

\section{MATERIALS AND METHODS}

\subsection{Wastewater treatment facilities}

The sewage treatment plant, named "WWTP Águilas" (Fig. 1) is a full-scale plant treating both domestic and industrial wastewater. It is located in the Region of Murcia (Southeast Spain) $\left(37^{\circ} 25^{\prime} 29^{\prime}\right.$ 'N , $01^{\circ} 34^{\prime} 46^{\prime}$ 'W), with a local orography which requires the use of 19 pumping stations, distributed in two large areas and named: (1) Trasiego; (2) La Cola Calle; (3) La Cola Carretera; (4) La Cola Playa; (5) Calabardina I; (6) Calabardina II; (7) Intermedio; (8) Delicias; (9) Arqueta Entrada Paseo Delicias; (10) Hornillo Playa; (11) Hornillo Calle; (12) Renfe; (13) Rubial; (14) Las Lomas; (15) Calarreona Hotel; (16) Calarreona Playa; (17) Marqués; (18) Matadero; and (19) Calarreona Camping. In order to avoid anomalies in the operation because of a power outage, there are seven emergency power generator sets.

This plant treats approximately $12,000 \mathrm{~m}^{3} \mathrm{~d}^{-1}$ of municipal wastewater for 29,777 equivalent inhabitants, and its treatment processes include two different lines:

(a) Conventional line - it consists of a conventional activated sludge process, with:

- Pretreatment: Initial screening with 2 manual-cleaning bars $(3 \mathrm{~cm}$ clearance for rough solids) and 3 self-cleaning sieves ( $6 \mathrm{~mm}$ clearance for fine solids).

- Grit and grease separation with aeration. 
- Primary clarification: Two circular settlers (18 m diameter). A reduction of $30 \%$ $\mathrm{BOD}_{5}$ and $65 \%$ suspended solids is achieved. Primary sludge is pumped to a sludge gravity thickener.

- Biological reactor: Two rectangular bioreactors with a total volume of 3,132 $\mathrm{m}^{3}$ and 6 aerators with a total power of $275 \mathrm{~kW}$.

- Secondary clarification: Two circular gravity clarifiers (22 m diameter). Settled sludge is collected and partially pumped $(70 \%)$ to the biological reactor. Secondary sludge is sent to the gravity thickener and clarified wastewater to an Accelator ${ }^{\mathbb{R}}$ settler (14 $\mathrm{m}$ diameter) prior to rapid sand filtration.

- Tertiary treatment: Three parallel open rapid sand filters with two units per filter and a central channel. Each filter is $6.04 \mathrm{~m}$ in length and $5.86 \mathrm{~m}$ in width, including the central channel. The filtration speed is $8 \mathrm{~m} \mathrm{~h}^{-1}$ and the maximum loss due to filter washing is $1.5 \%$. the total filtration surface is $75 \mathrm{~m}^{2}$ (Fig. 2).

(b) Membrane bioreactor line: It consists of an advanced wastewater treatment with microfiltration membranes:

- Pretreatment: Initial screening with 2 self-cleaning bars $(2 \mathrm{~cm}$ clearance for rough solids) and 2 self-cleaning sieves (3 mm clearance for fine solids). Sands are gravity removed.

- Lamination tank: It allows a 24-hours lamination flow with a total volume of $1,800 \mathrm{~m}^{3}$, pumping wastewater into an anoxic chamber.

- Anoxic chamber: One anoxic chamber with a volume of $363,5 \mathrm{~m}^{3}$, where denitrification is partially carried out.

- Biological reactor: One rectangular bioreactor with a volume of $1,050 \mathrm{~m}^{3}$ with three parts: aerobic, anaerobic, and facultative zones.

- Membrane tank: This unit has a total volume of $315 \mathrm{~m}^{3}$ with 10 submerged flat-sheet membrane modules EK-400 (Kubota Corporation, Japan) comprising a total of 4,000 membranes distributed into two lines at different heights within the membrane tank, and $3,560 \mathrm{~m}^{2}$ of effective microfiltration surface. The designed flow is $1,800 \mathrm{~m}^{3} \mathrm{~d}^{-1}$ and permeated wastewater is directly transferred for agricultural use.

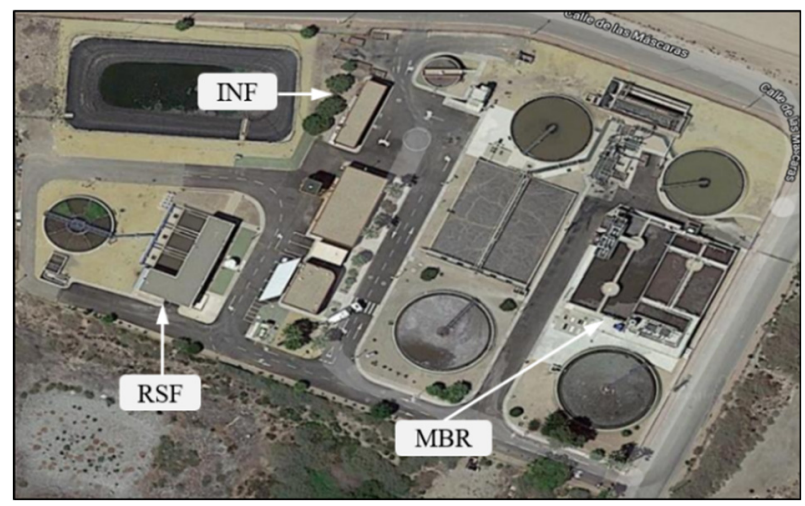

Figure 1: Operation of both wastewater treatment lines in WWTP Águilas, indicating where samples are collected: (INF) Influent; (MBR) Membrane bioreactor; (RSF) Rapid sand filter. 


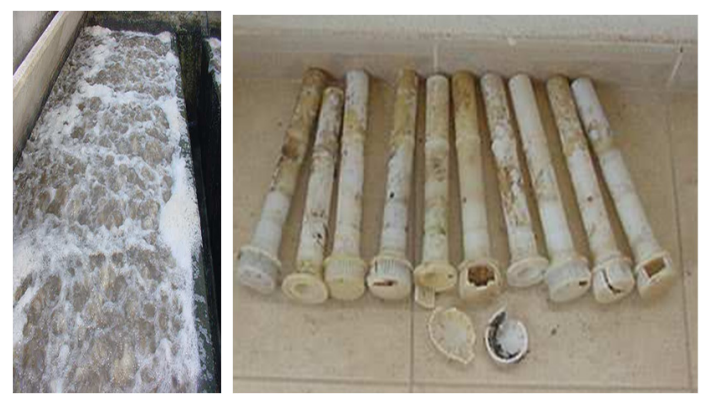

Figure 2: Rapid sand filtration.

Table 1: Sampling days and volumes.

\begin{tabular}{|l|c|c|c|}
\hline Sampling day & INF (l) & MBR (l) & RSF (l) \\
\hline 14 February 2018 & 3.78 & 3.50 & 3.56 \\
\hline 14 March 2018 & 4.98 & - & 3.75 \\
\hline 11 April 2018 & 3.20 & 5.49 & 5.24 \\
\hline 10 May 2018 & 3.97 & 4.93 & 5.35 \\
\hline 7 June 2018 & 4.41 & 4.83 & 4.47 \\
\hline 5 July 2018 & 4.62 & 4.71 & 4.80 \\
\hline 1 August 2018 & 3.42 & 3.77 & 3.87 \\
\hline 13 September 2018 & 3.82 & 3.78 & 3.89 \\
\hline 11 October 2018 & 4.25 & 3.82 & 3.86 \\
\hline 8 November 2018 & 5.37 & 3.81 & 3.84 \\
\hline 13 December 2018 & 3.72 & 3.40 & 3.41 \\
\hline 17 January 2019 & 3.32 & 3.86 & 3.87 \\
\hline 14 February 2019 & 5.20 & 4.71 & 4.77 \\
\hline 26 March 2019 & 4.23 & 4.11 & 3.98 \\
\hline 10 April 2019 & 3.91 & 3.41 & 3.33 \\
\hline 16 May 2019 & 3.81 & 4.12 & 3.74 \\
\hline 12 June 2019 & 3.78 & 3.84 & 3.34 \\
\hline 18 July 2019 & 3.68 & 9.20 & 3.77 \\
\hline Average & 4.18 & 4.32 & 4.04 \\
\hline Total & 73.47 & 75.29 & 72.74 \\
\hline
\end{tabular}

\subsection{Sample collection and processing}

The sewage plant has been monitored for 18 months with a total of 53 grab samples (Table 1); i.e., from 14th February 2018 to 18th July 2019, and accounting for 73.471 from INF, 75.291 from MBR, and 72.741 from RSF. 
Wastewater samples were always collected in the morning, between 9:00 $\mathrm{h}$ and 11:00 $\mathrm{h}$, in glass containers with metallic lid. Samples from MBR and RSF were directly vacuum filtered trough a Büchner funnel by means of a membrane filter (Prat Dumas, Couze-St-Front, France, $110 \mathrm{~mm} \varnothing$ pore size $0.45 \mu \mathrm{m}$ ), and microplastics included in INF samples were previously isolated by density separation with a $120 \mathrm{~g} \mathrm{l}^{-1} \mathrm{NaCl}$ solution (density $1.08 \mathrm{~g} \mathrm{ml}^{-1}$ ) as previously reported in Bayo et al. [19]. The mixture was placed into a 21 glass beaker with mechanical stirring for 20 min. Supernatant with floating particles was filtered through the same membrane filter and, after it was washed with bi-distilled water, content in the Petri dish was dried overnight in an air-forced stove.

In order to mitigate the risk of pollution, nitrile gloves and clean $100 \%$ cotton lab gowns were worn by analysts. Glass Petri dishes, both $40 \mathrm{~mm} \varnothing$ and $120 \mathrm{~mm} \varnothing$, were used and lab plastic devices were limited to the maximum, replacing plastic caps with aluminum foil when necessary. Laboratory benches and glassware were always twice washed with bi-distilled before each experiment. In order not to act as a source of microplastics, polyethylene containers for bi-distilled water were examined twice during the whole sampling campaign by vacuum filtering 1.51 of stored content. No microplastics were isolated from blank samples.

Possible microplastic particles were examined under an Olympus SZ-61TR Zoom Trinocular Microscope (Olympus Co., Tokyo, Japan), providing a superior image quality with a $10^{\circ}$ convergence angle at a working distance of $110 \mathrm{~mm}$, magnification range from $6.7 \mathrm{x}$ to $45 \mathrm{x}$ and LED lighting. This trinocular microscope was coupled to a Leica MC190 HD digital camera, with a maximum resolution of $1596 \times 1196$ pixels, 10 bits per color channel, 7.5 frames per second at full resolution, and $0.1 \mathrm{~ms}$ to $1 \mathrm{~s}$ exposure time.

The infrared spectra were acquired with a Thermo Nicolet 5700 Fourier transformed infrared (FTIR) spectrometer (Thermo Nicolet Analytical Instruments, Madison, WI, USA), provided with a deuterated triglycine sulfate (DTGS) detector and $\mathrm{KBr}$ detector. The spectra were collected with an average of 20 scans and a resolution of $16 \mathrm{~cm}^{-1}$ in the range of $4000-400 \mathrm{~cm}^{-1}$ wavelength. Spectra were controlled and evaluated by the OMNIC software package, by means of a reference polymer library containing spectra of all common polymers, together with literature [27]. Data were processed with the SPSS (Statistic Package for Social Science) 26.0 software.

\section{RESULTS AND DISCUSSION}

\subsection{Polymer types identified in wastewater samples}

Different types of microplastics were isolated in the INF, MBR, and RSF, and some microscopic images are depicted in Figs 3, 4, and 5, respectively. When microplastics from all sampling points were considered, a total of 14 different polymers were identified, all of them in the influent except for melamine (MUF) that was only identified in a MBR sample. The percentage of each polymer type found in the INF was: low-density polyethylene (LDPE) $(71.89 \%)$, followed by high-density polyethylene (HDPE) $(5.44 \%)$, acrylate (AC) (5.24\%), polypropylene (PP) $(5.22 \%)$, polystyrene (PS) (4.24\%), polyamide or nylon (NYL) $(2.56 \%)$, methacrylate (MCR) (1.76\%), poly(ethylene:propylene) (EPM) (1.07\%), biopolymer (BPL) $(0.62 \%)$, polyester (PEST) (0.56\%), polyvinyl (PV) $(0.50 \%)$, polyisobutylene (PIB) $(0.44 \%)$, and Teflon (PTFE) (0.44\%). Lares et al. [20] reported similar results; i.e., $63.9 \%$ of polyethylene in microplastic particles, from a municipal WWTP located in Finland with activated sludge process and a pilot-scale membrane bioreactor, and Long et al. [28] reported PP (30.2\%), PE (26.9\%), and PS (10.3\%) in the influent of seven 
WWTPs in China. According to Plastics Europe [29], the demand by resin type during 2018 was leaded by the polyolefins polyethylene and polypropylene, and these, plus polyester, are the major components of microplastics found in the aquatic environment [30].

In our study, the presence of acrylate in INF; i.e., poly(lauryl acrylate), poly(cyclohexyl acrylate), and poly(11-bromoundecyl acrylate), indicates its wide use in daily products, as commercial shower gels, peelings, waterproof sunscreen, or as a gelling agent in lipsticks and paint particles [31], [32]. As previously indicated, MUF was only isolated in a MBR sample, and RSF displayed three types of polymer: LDPE (58.67\%), PV (27.55\%), and NYL $(13.78 \%)$. Analysis of variance confirmed that the removal of LDPE from INF $(1.69 \pm 0.59$

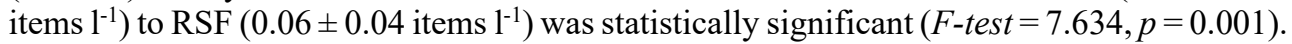
Other polymer types, as EPM and PV, previously reported in relatively high number in beach sediments [33] because their use in packaging and shipbuilding, respectively, only represented $1.07 \%$ and $0.50 \%$ in wastewater samples.

Some studies have pointed out that the enormous variability of polymeric plastic microparticles reported in different WWTPs has also to do with the use of oxidation processes reported to digest the organic matter in wastewater samples. In this sense, Carr et al. [34] found a potential loss of PE and PP after a digestion process, and Munno et al. [35] reported the loss of polyamide after a wet oxidation process with temperature higher than $60^{\circ} \mathrm{C}$.

The presence of styrene-butadiene rubber (SBR), the main component of car tires, was

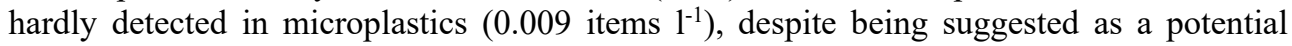
marker from car tire abrasion, the main source of microplastics into the environment [36]. Microparticles from car tire wear have a wide range of densities, as reported by Leads and Weinstein [37], depending on whether they come from raw recycled tire crumb rubber (1.13-1.16 $\mathrm{g} \mathrm{ml}^{-1}$ ) [38] or aggregated with road dust and mineral particles (up to $1.8 \mathrm{~g} \mathrm{ml}^{-1}$ ) [39], [40]. SBR is also difficult to be quantified by FTIR, due to the carbon black added as a filler [41], and rainfall scarcity in our Region could also contribute to its low detection, as the major fraction of road dust-associated microplastic particles is expected to be found in the runoff from the road verge generated during rainfall events [42].

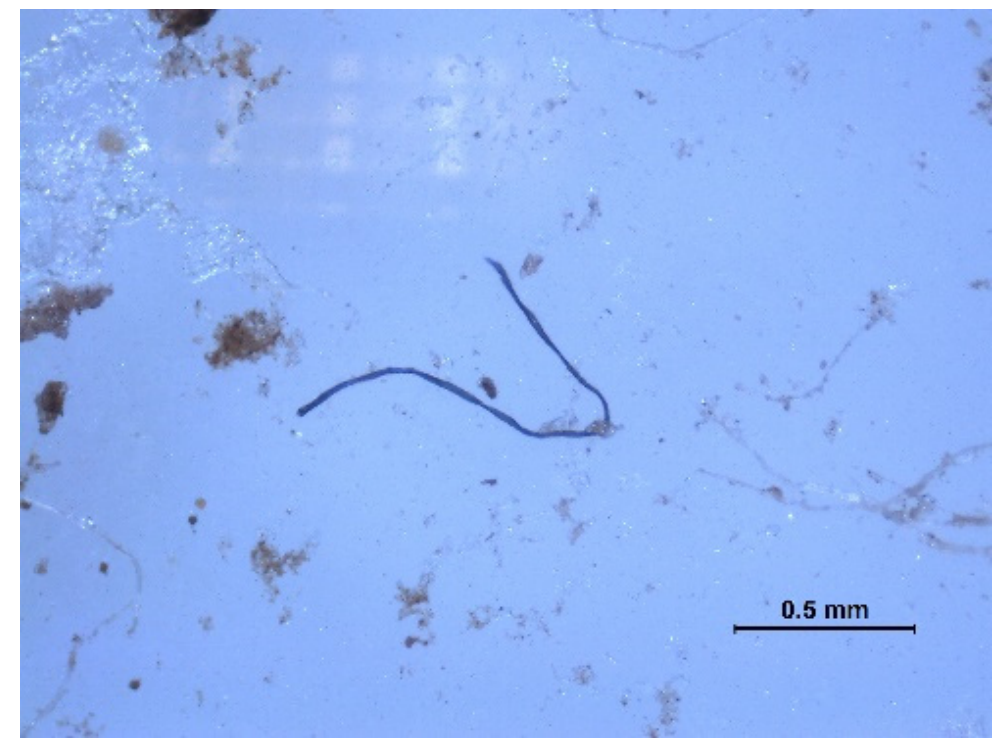

Figure 3: Nylon (NYL) blue fibre from influent (INF) (0.86 mm, 13 September 2018). 


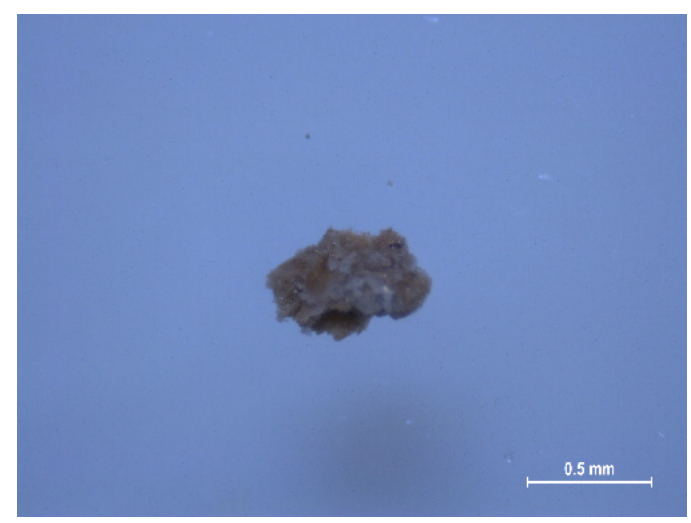

Figure 4: Melamine (MUF) brown fragment from membrane bioreactor (MBR) $(0.68 \mathrm{~mm}$, 7 June 2018).

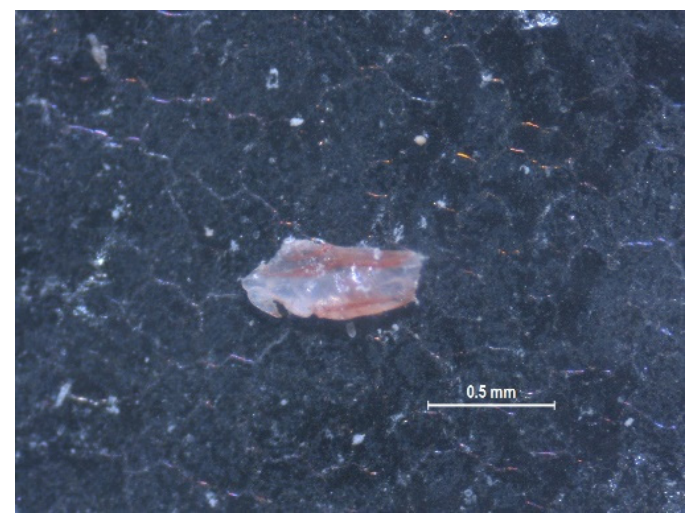

Figure 5: Low-density polyethylene (LDPE) pink film from rapid sand filter (RSF) (0.70 $\mathrm{mm}, 13$ September 2018).

\subsection{Shapes, sizes and colours of isolated microplastics}

The use of the stereomicroscope allowed a more exhaustive classification according to the shape of microplastics, with fibres (MFBs) (61.2\%) being the most recurrent form of microplastics in all wastewater samples (Fig. 3), followed by films (31.5\%) (Fig. 5), fragments (6.7\%) (Fig. 4), and beads (0.6\%) (Fig. 6), which represents a $38.8 \%$ of microplastic forms (MPPs) different to MFBs. These results are similar to that reported by Lares et al. [20] in a pilot-scale bioreactor operated in a WWTP in Finland. We also observed an increase in the ratios MFBs/Total microplastics and MPPs/Total microplastics from INF, accounting for $48.09 \%$ and $51.91 \%$, respectively, to MBR, $96.72 \%$ and $3.28 \%$, and RSF, $90.79 \%$ and $9.21 \%$, respectively. Because of the absence of plastic industries nearby the studied sewage treatment plant, it is clear that clothing fibres from washing machine effluents can bypass the treatment processes and escape into the aquatic environment [43], and this release has to do with many other factors; i.e., textile properties, washing conditions, or type of detergent and softener used [10], [14]-[16]. 
A $70.2 \%$ of microplastics larger than $1 \mathrm{~mm}$ corresponded to MFBs., and $58.9 \%$ of total microplastics were under $1 \mathrm{~mm}$. Only after MBR, microplastics smaller than $200 \mu \mathrm{m}$ were isolated. As depicted in Fig. 7, the percentage of each size interval was different according to the considered sampling point into the wastewater treatment plant. The main size range in all considered stages was between 1 and $2 \mathrm{~mm}$, accounting for a $28.2 \%, 37.3 \%$, and $36.8 \%$ for INF, MBR, and RSF, respectively. Average microplastic size displayed a statistically significant increase from INF $(1.05 \pm 0.05 \mathrm{~mm})$, to RSF $(1.15 \pm 0.08 \mathrm{~mm})$ and MBR $(1.39 \pm 0.15 \mathrm{~mm})(F$-test $=4.014, p=0.019)$ indicating the fibre selection made by advanced treatment technologies previously discussed.

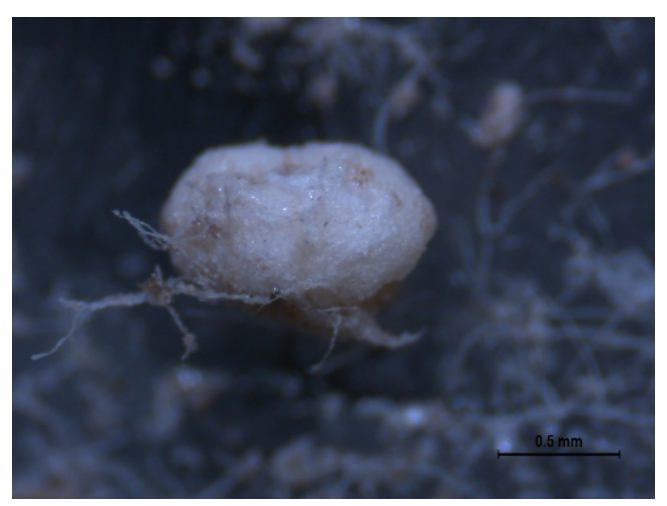

Figure 6: Polystyrene (PS) white bead from influent (INF) (1.10 mm, 14 February 2018).

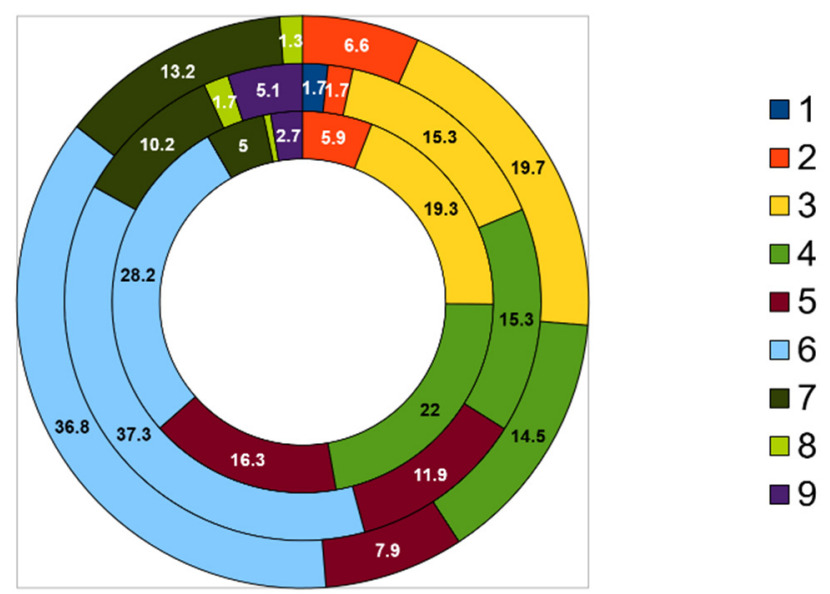

Figure 7: Size ranges according to the Spanish Environmental Ministry: (1) $0.2 \mathrm{~mm}$; (2) $0.2-0.4 \mathrm{~mm}$; (3) 0.4-0.6 mm; (4) 0.6-0.8 mm; (5) 0.8-1.0 mm; (6) $1.0-2.0 \mathrm{~mm}$; (7) $2.0-3.0 \mathrm{~mm}$; (8) $3.0-4.0 \mathrm{~mm}$; and (9) $4.0-5.0 \mathrm{~mm}$. Inner ring means RSF; Medium ring means MBR; Outer ring means INF (results expressed as a percentage). 
Most fragments were categorized as opaque $(71.9 \%)$, and most films as transparent (70.9\%). These results are similar to that reported by Leslie et al. [44] in WWTPs from The Netherlands. In the case of film forms, the average concentration decreased from INF $\left(1.7 \pm 0.6\right.$ items $\left.\mathrm{l}^{-1}\right)$ to RSF $\left(0.1 \pm 0.0\right.$ items $\left.\mathrm{l}^{-1}\right)$, totally disappearing in MBR effluent $(F$-test $=6.596, p=0.003)$.

\subsection{The removal rates of MBR and RSF}

A total of 480 microplastics were isolated from all wastewater samples, with an average concentration of $2.16 \pm 0.42$ items $\mathrm{l}^{-1}$. They represented $76.68 \%$ of total isolated microparticles, which corroborates the need of specific spectrometry techniques; i.e., FTIR, to successfully identify microplastics out of all types of microparticles captured in these studies [19], including calcium stearate, glycerine and lipid mediators from solidified soap, silicates, chipboard fragments, and so on [45]. Nevertheless, matching with IR spectra of standardized polymers from commercially available selected spectral libraries could be difficult, due to weathered and polluted surfaces of microplastics and interference with other compounds present in wastewater samples [46].

Statistically significant differences were observed between the average concentration of

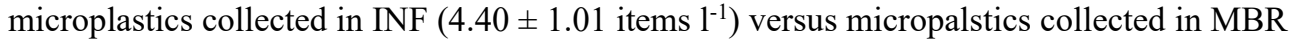

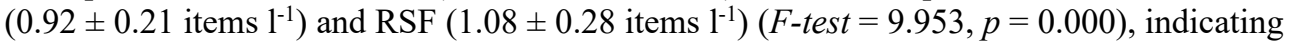
a clear removal with both technologies. The removal percentage for MBR was $79.01 \%$, higher than for RSF (75.49\%), although there were no statistically significant differences between both technologies $(F$-test $=0.195, p=0.661)$. Although both MPPs and MFBs proved to decrease through the sewage treatment plant, they displayed different removal

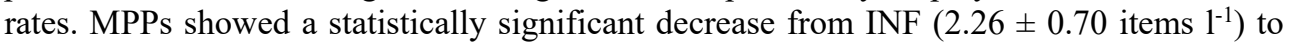

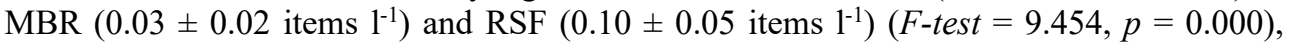
accounting for a $98.83 \%$ and $95.53 \%$ removal, respectively. In contrast, changes in MFBs

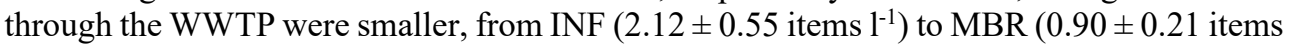
$\left.\mathrm{l}^{-1}\right)(57.61 \%)$ and $\operatorname{RSF}\left(0.98 \pm 0.27\right.$ items $\left.\mathrm{l}^{-1}\right)(53.83 \%)$, still with statistically significant differences $(F$-test $=3.214, p=0.049)$. Therefore, although a good performance in MPPs removal is achieved by both technologies, MFBs still bypass and escape into the aquatic environment, resulting in a global removal rate lower than that reported for a conventional activated sludge process [19]. Some reasons have been proposed to explain this fact; Leslie et al. [44] indicated that the high pressure applied to a MBR system could favor this escape, as well as their small size and morphology could enable them to longitudinally pass through the RSF [22], [45]. Also, a direct air pollution with MFBs derived from apparel articles and household dust released in open-air sewage treatment plants could be an important fact [47].

\section{CONCLUSIONS}

The results of this study allow us to conclude that advanced technologies, as membrane bioreactor, and tertiary treatments, as rapid sand filtration, proved to be more efficient removing particulate microplastics than microfibres, achieving a global microplastic elimination of $79.01 \%$ and $75.49 \%$, respectively, lower than that reported for conventional activated sludge processes; i.e., 90.3\% [19], and without statistical significant differences between them. As much as 14 different polymer types were isolated in wastewater samples, indicating the large amount of urban and industrial plastic sources used today, reaching the wastewater treatment plants in the form of microplastic particles, and matching to the demand by resin type indicated by the leading pan-European plastic trade association. 


\section{ACKNOWLEDGEMENT}

Authors sincerely acknowledge the grant from "Fundación Séneca" (20268/FPI/17) for the financial support of predoctoral student Sonia Olmos.

\section{REFERENCES}

[1] Carpenter, E.J. \& Smith, K.L., Plastics on the Sargasso Sea surface. Science, 175(4027), pp. 1240-1241, 1972.

[2] Thompson, R.C. et al., Lost at sea: Where is all the plastic? Science, 304(5672), pp. 838-838, 2004.

[3] Hidayaturrahman, H. \& Lee, T.G., A study on characteristics of microplastic in wastewater of South Korea: Identification, quantification, and fate of microplastics during treatment process. Marine Pollution Bulletin, 146, pp. 696-702, 2019.

[4] Eriksen, M. et al., Microplastic pollution in the surface waters of the Laurentian Great Lakes. Marine Pollution Bulletin, 77(1-2), pp. 177-182, 2013.

[5] He, D., Luo, Y., Lu, S., Liu, M., Song, Y. \& Lei, L., Microplastics in soils: analytical methods, pollution characteristics and ecological risks. TrAC Trends in Analytical Chemistry, 109, pp. 163-172, 2018.

[6] Peng, G., Zhu, B., Yang, D., Su, L., Shi, H. \& Li, D., Microplastics in sediments of the Changjiang Estuary, China. Environmental Pollution, 225, pp. 283-290, 2017.

[7] Iñíguez, M.E., Conesa, J.A. \& Fullana, A., Microplastics in Spanish table salt. Scientific Reports, 7(1), pp. 1-7, 2017.

[8] Toussaint, B. et al., Review of micro-and nanoplastic contamination in the food chain. Food Additives \& Contaminants: Part A, 36(5), pp. 639-673, 2019.

[9] Mintenig, S.M., Löder, M.G.J., Primpke, S. \& Gerdts, G., Low numbers of microplastics detected in drinking water from ground water sources. Science of the Total Environment, 648, pp. 631-635, 2019.

[10] Prata, J.C., Airborne microplastics: consequences to human health? Environmental Pollution, 234, pp. 115-126, 2018.

[11] Bayo, J., Guillén, M., Olmos, S., Jiménez, P., Sánchez, E. \& Roca, M.J., Microplastics as vector for persistent organic pollutants in urban effluents: The role of polychlorinated biphenyls. International Journal of Sustainable Development and Planning, 13(4), pp. 671-682, 2018.

[12] Bayo, J., Olmos, S. \& López-Castellanos, J., Non-polymeric chemicals or additives associated with microplastic particulate fraction in a treated urban effluent. WIT Transactions on The Built Environment, 179, pp. 303-314, 2018.

[13] Andrady, A.L., Environmental Sustainability of Plastics, John Wiley, 2016.

[14] Browne, M.A. et al., Accumulation of microplastic on shorelines worldwide: sources and sinks. Environmental Science \& Technology, 45(21), pp. 9175-9179, 2011.

[15] Almroth, B.M.C., Åström, L., Roslund, S., Petersson, H., Johansson, M. \& Persson, N. K., Quantifying shedding of synthetic fibers from textiles; a source of microplastics released into the environment. Environmental Science and Pollution Research, 25(2), pp. 1191-1199, 2018.

[16] De Falco, F. et al., Evaluation of microplastic release caused by textile washing processes of synthetic fabrics. Environmental Pollution, 236, pp. 916-925, 2018.

[17] Bayo, J., Martínez, A., Guillén, M., Olmos, S., Roca, M.J. \& Alcolea, A., Microbeads in commercial facial cleansers: threatening the environment. Clean-Soil, Air, Water, 45(7), pp. 1-11, 2017. 
[18] Bayo, J., Olmos, S., López-Castellanos, J. \& Alcolea, A., Microplastics and microfibers in the sludge of a municipal wastewater treatment plant. International Journal of Sustainable Development and Planning, 11(5), pp. 812-821, 2016.

[19] Bayo, J., Olmos, S. \& López-Castellanos, J., Microplastics in an urban wastewater treatment plant: The influence of physicochemical parameters and environmental factors. Chemosphere, 238, 124593, 2020.

[20] Lares, M., Ncibi, M.C., Sillanpää, M. \& Sillanpää, M., Occurrence, identification and removal of microplastic particles and fibers in conventional activated sludge process and advanced MBR technology. Water Research, 133, pp. 236-246, 2018.

[21] Dvořák, L., Svojitka, J., Wanner, J. \& Wintgens, T., Nitrification performance in a membrane bioreactor treating industrial wastewater. Water Research, 47(13), pp. 4412-4421, 2013.

[22] Talvitie, J., Mikola, A., Koistinen, A. \& Setälä, O., Solutions to microplastic pollutionRemoval of microplastics from wastewater effluent with advanced wastewater treatment technologies. Water Research, 123, pp. 401-407, 2017.

[23] Michielssen, M.R., Michielssen, E.R., Ni, J. \& Duhaime, M.B., Fate of microplastics and other small anthropogenic litter (SAL) in wastewater treatment plants depends on unit processes employed. Environmental Science: Water Research \& Technology, 2(6), pp. 1064-1073, 2016.

[24] Gündoğdu, S., Çevik, C., Güzel, E. \& Kilercioğlu, S., Microplastics in municipal wastewater treatment plants in Turkey: a comparison of the influent and secondary effluent concentrations. Environmental Monitoring and Assessment, 190(11), 626 pp., 2018.

[25] Tagg, A.S., Sapp, M., Harrison, J.P. \& Ojeda, J.J., Identification and quantification of microplastics in wastewater using focal plane array-based reflectance micro-FT-IR imaging. Analytical Chemistry, 87, pp. 6032-6040, 2015.

[26] Edo, C., González-Pleiter, M., Leganés, F., Fernández-Piñas, F. \& Rosal, R., Fate of microplastics in wastewater treatment plants and their environmental dispersion with effluent and sludge. Environmental Pollution, 259, pp. 113837, 2020.

[27] Hummel, D.O., Atlas of Plastics Additives: Analysis by Spectrometric Methods, Springer: Berlin/Heidelberg, 537 pp., 2002.

[28] Long, Z. et al., Microplastic abundance, characteristics, and removal in wastewater treatment plants in a coastal city of China. Water Research, 155, pp. 255-265, 2019.

[29] Plastics - the Facts 2018, An analysis of European plastics production, demand and waste data. www.plasticseurope.org/application/files/6315/4510/9658/Plastics_the facts_2018_AF_web.pdf. Accessed on: 3 Feb. 2020.

[30] Lee, $\bar{H}$., Shim, W.J. \& Kwon, J.H., Sorption capacity of plastic debris for hydrophobic organic chemicals. Science of the Total Environment, 470, pp. 1545-1552, 2014.

[31] Liebezeit, G. \& Dubaish, F., Microplastics in beaches of the East Frisian islands Spiekeroog and Kachelotplate. Bulletin of Environmental Contamination and Toxicology, 89(1), pp. 213-217, 2012.

[32] Chae, D.H., Kim, I.S., Kim, S.K., Song, Y.K. \& Shim, W.J., Abundance and distribution characteristics of microplastics in surface seawaters of the Incheon/Kyeonggi coastal region. Archives of Environmental Contamination and Toxicology, 69(3), pp. 269-278, 2015.

[33] Bayo, J., Rojo. D. \& Olmos, S., Abundance, morphology and chemical composition of microplastics in sand and sediments from a protected coastal area: The Mar Menor lagoon (SE Spain). Environmental Pollution, 252, pp. 1357-1366, 2019. 
[34] Carr, S.A., Liu, J. \& Tesoro, A.G., Transport and fate of microplastic particles in wastewater treatment plants. Water Research, 91, pp. 174-182, 2016.

[35] Munno, K., Helm, P.A., Jackson, D.A., Rochman, C. \& Sims, A., Impacts of temperature and selected chemical digestion methods on microplastic particles. Environmental Toxicology and Chemistry, 37(1), pp. 91-98, 2018.

[36] Sommer, F. et al., Tire abrasion as a major source of microplastics in the environment. Aerosol and Air Quality Research, 18, pp. 2014-2028, 2018.

[37] Leads, R.R. \& Weinstein, J.E., Occurrence of tire wear particles and other microplastics within the tributaries of the Charleston Harbor Estuary, South Carolina, USA. Marine Pollution Bulletin, 145, pp. 569-582, 2019.

[38] Rhodes, E.P., Ren, Z. \& Mays, D.C., Zinc leaching from tire crumb rubber. Environmental Science \& Technology, 46(23), pp. 12856-12863, 2012.

[39] Klöchner, P., Reemtsma, T., Eisentraut, P., Braun, U., Ruhl, A.S. \& Wagner, S., Tire and road wear particles in road environment-quantification and assessment of particle dynamics by $\mathrm{Zn}$ determination after density separation. Chemosphere, 222, pp. 714-721, 2019.

[40] Unice, K.M., Kreider, M.L. \& Panko, J.M., Comparison of tire and road wear particle concentrations in sediment for watersheds in France, Japan, and the United States by quantitative pyrolysis GC/MS analysis. Environmental Science \& Technology, 47(15), pp. 8138-8147, 2013.

[41] Haave, M., Lorenz, C., Primpke, S. \& Gerdts, G., Different stories told by small and large microplastics in sediment-first report of microplastic concentration in an urban recipient in Norway. Marine Pollution Bulletin, 141, pp. 501-513, 2019.

[42] Vogelsang, C. et al., Microplastics in road dust-characteristics, pathways and measures. Report from Norwegian Institute for Water Research, pp. 170, 2019.

[43] Ladewig, S.M., Bao, S. \& Chow, A.T., Natural fibers: A missing link to chemical pollution dispersion in aquatic environments. Environmental Science \& Technology, 49, pp. 12609-12610, 2015.

[44] Leslie, H.A., Brandsma, S.H., Van Velzen, M.J.M. \& Vethaak, A.D., Microplastics en route: Field measurements in the Dutch river delta and Amsterdam canals, wastewater treatment plants, North Sea sediments and biota. Environmental International, 101, pp. 133-142, 2017.

[45] Ziajahromi, S., Neale, P.A., Rintoul, L. \& Leusch, F.D., Wastewater treatment plants as a pathway for microplastics: Development of a new approach to sample wastewater-based microplastics. Water Research, 112, pp. 93-99, 2017.

[46] Gies, E.A. et al., Retention of microplastics in a major secondary wastewater treatment plant in Vancouver, Canada. Marine Pollution Bulletin, 133, pp. 553-561, 2018.

[47] Zobkov, M. \& Esiukova, E., Microplastics in Baltic bottom sediments: Quantification procedures and first results. Marine Pollution Bulletin, 114(2), 724-732, 2017. 